\title{
BMJ Open Quality Impact and costs of a hepatitis $C$ virus screening programme for adults hospitalised at an academic medical centre
}

\author{
Timothy J Whitman, ${ }^{1}$ Cindy D Noyes, ${ }^{1}$ Andrew J Hale, ${ }^{1}$ Devika Singh, ${ }^{1}$ \\ Stephen G DeVoe (D) , ${ }^{2}$ Allen B Repp (D) , ${ }^{2}$ Kristen K Pierce, ${ }^{1}$ Louis B Polish, ${ }^{1}$ \\ Beth D Kirkpatrick, ${ }^{1}$ Jean Dejace, ${ }^{1}$ Lindsay M Smith, ${ }^{1}$ Tim Lahey, ${ }^{1}$ \\ Christopher D Huston, ${ }^{1}$ Laura J Catoe, ${ }^{1}$ Prateek Ghatage, ${ }^{1}$ Sean Bullis, ${ }^{1}$ \\ W Kemper Alston ${ }^{1}$
}

To cite: Whitman TJ, Noyes CD, Hale AJ, et al. Impact and costs of a hepatitis $C$ virus screening programme for adults hospitalised at an academic medical

centre. BMJ Open Quality 2021;10:e001248. doi:10.1136/ bmjoq-2020-001248

Received 26 0ctober 2020 Revised 26 January 2021 Accepted 4 February 2021
Check for updates

(C) Author(s) (or their employer(s)) 2021. Re-use permitted under CC BY-NC. No commercial re-use. See rights and permissions. Published by BMJ.

${ }^{1}$ Division of Infectious Diseases, Department of Medicine, The Robert Larner, MD College of Medicine at the University of Vermont, Burlington, Vermont, USA

${ }^{2}$ Department of Medicine Quality Program, The Robert Larner, MD College of Medicine at the University of Vermont, Burlington, Vermont, USA

Correspondence to Dr Timothy J Whitman; timothy.whitman@uvmhealth. org

\section{INTRODUCTION}

Approximately $1.7 \%$ of the US population has chronic hepatitis $\mathrm{C}$ virus (HCV) infection, but among adults born between 1945 and 1965 prevalence increases to $3.25 \%$, and this birth cohort accounts for almost $75 \%$ of the total burden of HCV. ${ }^{12}$ The availability of effective direct-acting antiviral (DAA) therapy for HCV makes screening, linkage to care and treatment a national priority. The Centers for Disease Control and Prevention (CDC) and US Preventative Services Task Force (USPSTF) have recommended one-time HCV screening for persons born between 1945 and $1965,{ }^{23}$ yet only 14\%-17\% of this cohort has been screened for HCV. ${ }^{45}$

To improve adherence to HCV screening recommendations for patients hospitalised at our medical centre, the Division of Infectious Diseases (ID) at the University of Vermont Medical Center (UVMMC) undertook a quality improvement (QI) initiative to screen patients born between 1945 and 1965 who were seen by the ID Consultation Service. UVMMC is a 562-bed academic medical centre affiliated with the Robert Larner MD College of Medicine at the University of Vermont (UVM) and serves over 1 million patients in Vermont and New York State. Recognising that the baseline prevalence rate of HCV is $1.45 \%$ of adults in Vermont and $1.49 \%$ in New York, ${ }^{1}$ we hypothesised that screening hospitalised patients seen by the ID Consultation Service would increase screening rates, identify undiagnosed HCV infections and link patients to care.

\section{METHODS}

We developed a protocol to identify patients born between 1945 and 1965 seen by the
ID Consultation Service, perform HCV screening and link patients to outpatient care. All patients receiving a consult were being treated for conditions unrelated to HCV (eg, osteomyelitis, endocarditis, urinary tract infections). ID physicians reviewed the electronic medical record (EMR) (Epic Systems Corporation; Verona, Wisconsin, USA) for evidence of prior screening, then offered a one-time HCV antibody screening to previously unscreened patients. All patients with a positive HCV antibody test underwent confirmatory HCV-RNA PCR viral load testing. Patients were notified of results either during hospitalisation or via a letter if discharged before available test results. Patients with previously or newly diagnosed chronic HCV infection were offered follow-up treatment with the UVMMC ID Clinic. Programme costs were calculated based on Medicare reimbursement for laboratory tests (a cost surrogate), estimated physician and analyst hours, and the mean hourly wage for physicians (\$98.02) and computer systems analysts $(\$ 40.25)$ reported by the US Bureau of Labor Statistics. ${ }^{6}$

A secure database (Access 2016; Microsoft Corporation; Redmond, Washington, USA) was used to track screening results and basic demographic information to allow outpatient clinic staff to coordinate follow-up care as needed. According to the policy defining research activities at UVM, this project met criteria for operational improvement activities exempt from ethics review.

Prior to initiating our screening protocol, and monthly during our ID Division meetings, we reviewed the goals, objectives and progress updates to raise awareness among 


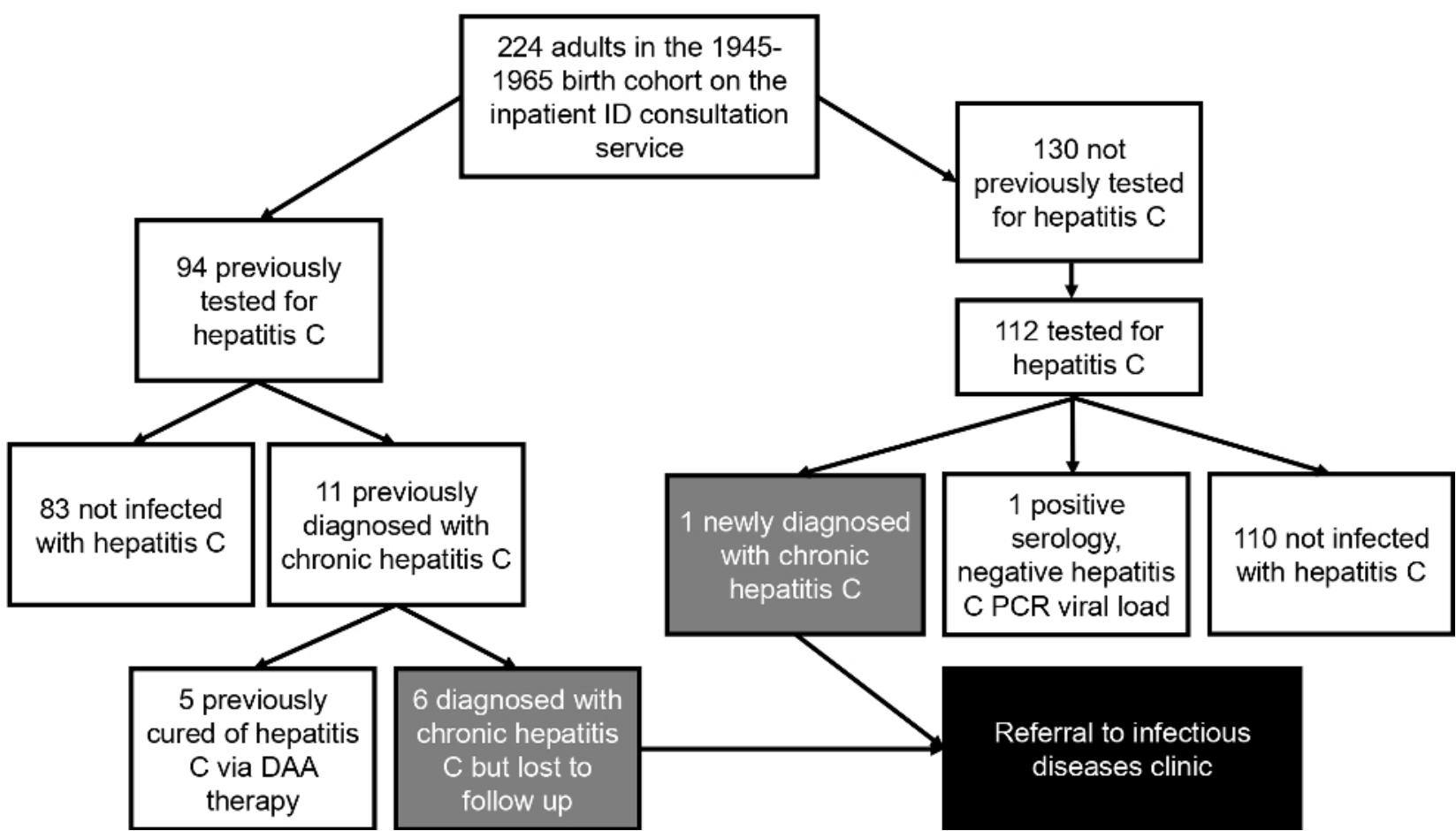

Figure 1 Results of hepatitis C virus screenings for hospitalised patients in the 1945-1965 birth cohort who were on the University of Vermont Medical Center Infectious Diseases (ID) Consultation Service; May 2019-February 2020. DAA, directacting antiviral.

physicians. As this was an ID physician-directed protocol, nursing staff were not part of this effort.

\section{RESULTS}

From May 2019 through February 2020, ID providers were consulted on 541 patients in the 1945-1965 birth cohort and enrolled $224(41 \%)$ in this project (figure 1$)$. Ninety-four $(42 \%)$ of these patients had been screened for HCV prior to admission and $11(12 \%)$ had previously been diagnosed with HCV with 6 having evidence of active infection. Of the $130(58 \%)$ patients with no documented prior HCV screening, $112(86 \%)$ had a protocoldriven HCV antibody screening serology performed during their hospitalisation, and $1(1 \%)$ patient had positive results on both the HCV antibody and PCR testing. Screening was not performed on 18 (14\%) inpatients due to transition to comfort measures, discharge prior to testing or primary team non-adherence with recommendations. Out of the seven patients with newly identified or previously known HCV infection, none attended the postdischarge scheduled outpatient appointments and none received DAA therapy. The reasons for lack of follow-up included opioid use disorder, lack of transportation and more urgent medical concerns. We estimated the HCV screening initiative required 27 physician-hours and 10 analyst-hours to complete, resulting in \$3049 in labour costs and $\$ 1939$ in laboratory costs.

\section{DISCUSSION}

An ID physician-driven QI initiative aimed at increasing HCV screening and treatment rates in hospitalised patients in the 1945-1965 birth cohort identified only one new patient with HCV and six previously diagnosed patients with untreated chronic HCV infection. All these patients were lost to follow-up post-discharge secondary to active drug use and social determinants of health, both well-described concerns in patients with chronic HCV infection. Our QI initiative cost approximately $\$ 5000$ in labour and laboratory costs with essentially no immediate impact on the HCV cascade of care. Despite our inability to enrol patients in further HCV care, the initiative did present the opportunity for providers to re-engage patients with known HCV and offer them treatment.

At least $42 \%$ of the patients included in this initiative had previously been screened for HCV. The prevalence of HCV (12\%) in those patients who had been screened prior to admission was predominantly attributable to prior intravenous drug use and was higher than the region's general population $(1.45 \%)$, but lower than the prevalence reported in other samples of hospitalised patients. ${ }^{1} 7$ This high baseline preadmission screening rate may reflect prior outpatient HCV screening programmes in our primary care clinics and likely reduced the effectiveness of this inpatient screening programme. ${ }^{8}$ Screening strategies targeting hospitalised patients may be more effective in regions where HCV prevalence rates are higher and outpatient HCV screening is less frequent. ${ }^{1}$ Screening protocols in such regions would require periodic updates as $\mathrm{HCV}$ 
rates change and screening recommendations evolve to include a larger birth cohort. ${ }^{19}$

Our findings have several limitations. First, in this prospective QI initiative, outpatient records were not available for 40 of the 130 patients without known prior screening. They may have undergone HCV screening prior to admission, which would raise the baseline testing rate above the $42 \%$ we measured. Second, due to competing information technology demands at the time of our initiative, we were not able to incorporate automated EMR alerts to identify and prompt screening for eligible patients and instead relied on physicians remembering to recommend screening and engage with patients, leading to missed opportunities. ${ }^{10} 11$ These missed opportunities for screening decreased our sample size and may have impacted our baseline HCV testing positivity rate of only $1 \%$. Future efforts should include team-based measures to improve the continuum of care in outpatient populations with higher prevalence. Although previous evidence that HCV screening programmes represent a cost-effective strategy, ${ }^{12}$ our initiative to screen hospitalised patients in a low-prevalence region with high baseline screening rates failed to improve screening rates and linkage to care for patients with chronic HCV infection. To address the burden of HCV in the USA, we suggest leveraging EMR clinical decision support and interprofessional teams in the outpatient setting to diagnose HCV infection and link patients to care in accordance with CDC and USPSTF recommendations.

Contributors TJW, CDN, AJH, DS, WKA, ABR and SGD served on a divisional QI subcommittee and conceived the intervention discussed in the manuscript, which was then reviewed and approved by all coauthors. TJW, CDN, AJH, DS, KKP, LBP, BDK, JD, LMS, TL, CDH, LJC, PG, SB and WKA are Infectious Diseases providers at our academic medical centre who provided direct patient care and related care follow-up. TJW, SGD and ABR led the drafting of this manuscript with significant contributions from the entire coauthor team.

Funding The authors have not declared a specific grant for this research from any funding agency in the public, commercial or not-for-profit sectors.

Competing interests None declared.

Patient and public involvement Patients and/or the public were not involved in the design, or conduct, or reporting, or dissemination plans of this research.
Patient consent for publication Not required.

Provenance and peer review Not commissioned; externally peer reviewed.

Open access This is an open access article distributed in accordance with the Creative Commons Attribution Non Commercial (CC BY-NC 4.0) license, which permits others to distribute, remix, adapt, build upon this work non-commercially, and license their derivative works on different terms, provided the original work is properly cited, appropriate credit is given, any changes made indicated, and the use is non-commercial. See: http://creativecommons.org/licenses/by-nc/4.0/.

ORCID iDs

Stephen G DeVoe http://orcid.org/0000-0002-1760-7752

Allen B Repp http://orcid.org/0000-0001-7513-532X

\section{REFERENCES}

1 Rosenberg ES, Hall EW, Sullivan PS, et al. Estimation of State-Level prevalence of hepatitis $C$ virus infection, us states and district of Columbia, 2010. Clin Infect Dis 2017;64:1573-81.

2 Smith BD, Morgan RL, Beckett GA, et al. Recommendations for the identification of chronic hepatitis $C$ virus infection among persons born during 1945-1965. MMWR Recomm Rep 2012;61:1-32.

3 Moyer VA, U.S. Preventive Services Task Force. Screening for hepatitis C virus infection in adults: U.S. preventive services Task force recommendation statement. Ann Intern Med 2013;159:349-57.

4 Kasting ML, Giuliano AR, Reich RR, et al. Hepatitis C virus screening trends: a 2016 update of the National health interview survey. Cancer Epidemiol 2019;60:112-20.

5 Patel EU, Mehta SH, Boon D, et al. Limited coverage of hepatitis C virus testing in the United States, 2013-2017. Clin Infect Dis 2019;68:1402-5.

6 US Bureau of Labor Statistics. Occupational employment statistics, 2020. Available: https://www.bls.gov/oes/home.htm [Accessed 12 Aug 2020].

7 Austin GE, Jensen B, Leete $\mathrm{J}$, et al. Prevalence of hepatitis C virus seropositivity among hospitalized US veterans. Am J Med Sci 2000;319:353-9.

8 MacLean CD, Berger C, Cangiano ML, et al. Impact of electronic reminder systems on hepatitis $\mathrm{C}$ screening in primary care. J Viral Hepat 2018;25:939-44.

9 Chou R, Dana T, Fu R, et al. Screening for hepatitis C virus infection in adolescents and adults: updated evidence report and systematic review for the US preventive services Task force. JAMA 2020;323:976-91.

10 Jonas MC, Rodriguez CV, Redd J, et al. Streamlining screening to treatment: the hepatitis $C$ cascade of care at Kaiser Permanente Mid-Atlantic states. Clin Infect Dis 2016;62:1290-6.

11 Shahnazarian V, Karu E, Mehta P. Hepatitis C: improving the quality of screening in a community hospital by implementing an electronic medical record intervention. BMJ Qual Improv Rep 2015;4:u208549. w3409.

12 Coretti S, Romano F, Orlando V, et al. Economic evaluation of screening programs for hepatitis $C$ virus infection: evidence from literature. Risk Manag Healthc Policy 2015;8:45-54. 